\title{
CONSTRUCTING INTERNATIONAL RELATIONS BETWEEN ISRAEL AND JORDAN: THE CASE OF THE 'EILAT PROJECT'
}

\author{
Ronen SHAY, PhD student
}

Babes-Bolyai University, Faculty of European Studies, Romania ronen.fm102@gmail.com

\begin{abstract}
Contrary to the Egyptian-Israeli peace treaty, the treaty between Israel and Jordan reflects aspects of normalization. Mechanisms for neighborly relations were established, and foundations for economic cooperation in the tourism industry were created. A new form of a friendly and robust relationship was established in 2014 with the Eilat project's implementation, which allowed 2000 Jordanian citizens to work in the hospitality industry in Eilat, Israel. Security issues and fear of terror attacks, bureaucracy, nationality, and citizenship are still part of this sensitive endeavor; however, it seems that the two countries are headed towards a warmer peace.
\end{abstract}

Keywords: Cold/warm Peace, Hospitality, Nationality, Security and Bureaucracy, The Eilat Project.

\section{Introduction}

October 26, 2020, marked the 26th anniversary of the Israeli-Jordanian peace agreement. In essence, the treaty profoundly altered the nature of the Israeli-Jordanian relationship, increasing safety, stability, and U.S. interests in a chaotic region. However, the peace- building process did not manifest in the way it was envisioned. The expectation that the peace agreement would lead to warm and neighborly relations based on coexistence, mutual cooperative endeavors, and an acceptance of the other has failed to materialize. In practice, despite hopes and aspirations, the peace between the nations has remained “cold”( Sütalan 2015; Sallam and Ofir Winter 2017). 
Due to the rarity of cooperation between the two states, "the Eilat project" signifies a new era in Israel and Jordan's relations since it permits Jordanians to cross the border to work in Eilat's hospitality industry. Eilat, the southernmost city of Israel, hosts 12,000 hotel rooms, averaging occupancy between 65\%-75\% (2005-2015), including hotels from one star to five stars deluxe. Till the initiation of the project, the hotel sector relied on illegal African migrant workers. The constant shortage of employees, especially in the needed departments like housekeeping and stewarding, created continuous chaos, and hotels could not function at maximum capacity. Hence, Israel decided to explore a new commercial frontier and agreed to incorporate Jordanian employees into the Israeli hospitality industry. Incorporating the Jordanian workers enabled hotels to be fully operational and provided work to Aqaba's citizens.

As a recreation area, Eilat's economy relies on tourism. $80 \%$ of the city business depends on the hospitality industry. Thus, when the city is filled with tourists, it helps the city's growth and development. Jordan is known to be an exporter of workforce to the Arab states of the Persian Gulf, especially in the hospitality industry. The 'Arab Spring' caused inflation and unemployment that were realized in feelings of discontent and frustration. Therefore, the Eilat project guaranteed work to 2000 people and ensured a good life for their extended families. The project has a positive economic impact on Eilat and Aqaba as it lowers unemployment, enriches the economy, and enables the hotel industry's operation. The initiative opened new business horizons, allowed further investments, more endeavors, and helped many families from both sides of the boarders to build businesses and prosper.

This paper examines the new endeavor between Israel and Jordan, two states that usually refrain from collaboration. It sheds light on the power of cross-cultural communication in cultivating feelings of trust and respect between people from different religions and nationalities. ${ }^{3}$ Cultural understanding of the modern multicultural workforce has been studied extensively since the beginning of globalization. Yet, this paper emphasizes distinctive features that derive due to the cold peace (e.g., national animosity, security hazards, bureaucracy, and national affiliation) that were not investigated in the realm of a global multicultural workforce. The study objective is to detect novel and practical ways to sustain and improve cold

\footnotetext{
${ }^{3}$ The study is based on the author's $\mathrm{PhD}$ research paper.
} 
peace. It examines the opportunities and shortcomings of implementing the project model. One cannot deny that security issues and bureaucracy will always be an integral part of this initiative. For the foreseeable future, monitoring, screening, and inspections are vital and essential. However, security and peace are ensured by physical and diplomatic arrangements and by engraving and anchoring the notion of peace in people's minds, hearts, and souls (Avineri 2000). Hence, mutual economic interests have enabled the continuation of the project despite political disagreements or security hazards.

The paper aims to research the Eilat project's national, security, and bureaucracy aspects since they constitute a profound part of Israel and Jordan relations. The ultimate goal is to show that common interests and social interaction are steps in the right direction to guarantee warmer peace and to safeguard the initiative's progress. Namely, true peace is achieved through human connections. Social encounters generate trust, kinship, and closeness and eradicate fears, apprehensions, prejudice, and misconceptions.

It is noteworthy that this paper is based on the author's $\mathrm{PhD}$ research paper. The dissertation examined the cross-cultural understanding of the contemporary global multicultural workforce by investigating the Eilat project. It studied the prospects and limitations of implementing the project model and explored its replicability in other regions and countries. This paper focuses on one theme (i.e., Israel and Jordan relations) that was introduced in the thesis. The paper is organized as follows. The next section presents the literature review, the theories, and approaches that constitute this study's base. Subsequently, the research methodology is described, then the findings, discussion, and conclusions that emerged from the study are presented.

\section{Literature Review}

The belligerent history between Israel and Jordan and the ongoing Israel-Palestinian conflict indicate that security issues are deeply rooted in the project's implementation. Stakeholders (e.g., politicians, hoteliers, and administrators) acknowledge that peace is fragile; hence, security problems can paralyze Eilat's hospitality industry. Interested parties also raise the 
concern that people might take advantage of the project to commit terror attacks. ${ }^{4}$ Since fears and concerns constitute a profound portion of the project, individuals from both sides of the border realize that bureaucracy ensures its safety. Hence, the project is continuously controlled and monitored and includes strict protocols, background checks, rules, procedures, and codes of conduct.

\subsection{Security issues and bureaucracy}

International borders are dynamic across time and space. They are formed, removed, changed, and articulated via countless material and social mechanisms. To wit, disagreements, commerce, incorporation, and omission impact how borders between neighboring states are regulated (Hataley and Leuprecht 2018). Borders are institutions with specific rules and behaviors that shape their functionality, preservation, and modification (Newman 2003). They affect how people think of frontiers, while their role and evolution reflect states' values and interests. Yet, distinctly, borders are human constructs, generated to control human behavior in a spatial context (Popescu 2012).

Border management forms an equilibrium between security and the legal flow of people and goods. This concept is based on the understanding that friction and conflict prevail between the need to avert unwelcome people and unwanted goods from crossing borders and economic strength that a state obtains through trade and travel. Hence, cross-border management offers opportunities to improve security while simultaneously enhancing the flow of legal passengers and goods through policies, programs, regulations, and activities (Gerstein et al 2008). Border management is founded on three principles that preserve the delicate balance between security and economic strength.

The first notion is integrating safety and the flow of people and trade. Second, creating an integrated, layered approach, developing an inclusive system that comprises planning, equipment, and training. Third, forming a border management system requires unity of effort across all related governmental and non- governmental stakeholders-notably, interested parties with responsibilities or gains in national borders. Thus, command, control, and

\footnotetext{
${ }^{4}$ The comments are based on interviewees' remarks that are stated in the researcher's $\mathrm{PhD}$ paper.
} 
communication that admit collaboration and synchronization among numerous interagency organizations and from the national to the local level are vital to border control (Gerstein et al 2008).

Ultimately, border policy modifications result from negotiation between stakeholders, who share mutual interests, viewpoints, and values. The procedure is not exclusive to elites (e.g., politicians, legislators, people of means), nor is it linear. Instead, it is a variable with multiple nonstate actors (e.g., business people, administrators, entrepreneurs) whose varied social insights are mirrored in the outcome. Therefore, borders reflect the historical, political, and cultural framework of a state. They echo the societies and cultures they encompass and mirror specific social relationships in space and time (Hataley and Leuprecht 2018).

This paper demonstrates that border control's complexity must be handled from both sides of the border. It has to be collaborative management, including domestic (i.e., intra-service and inter-agency cooperation) and international dimensions (i.e., transnational collaboration) (Rusdiyant 2017). Moreover, bureaucracy and strict management offer opportunities to enhance security while concurrently improving cooperation, collaboration, and mutual interests.

\subsection{Nationality and citizenship}

This study's primary aim is to illustrate that warmer peace could be achieved through interpersonal relationships and personal bonds. The cultural theory (Douglas 1978) emphasizes how groups in society interpret danger and build trust or distrust in institutions molding and regulating risk. The approach offers a way of decoding how and why individuals form judgments about danger and threat and stresses that opinions are not formed independently of social context. Hence, views of risk and uncertainty can be modified via social interaction and close encounters, and peaceful relations between culturally and nationally contradicting societies can be achieved through human connections. Thus, though Israelis and Jordanians hold different political principles and beliefs, they can collaborate and form close relations.

The peace agreement between Israel and Jordan was founded on peace-building instead of conflict resolution or management. After decades of hostility and suspicion, it is clear that the mental, consciousness-based transition from conflict to peace is not stress-free. Namely, people 
cannot be coerced to promptly erase feelings of resentment, which accumulated over years of war (Sallam and Winter 2017). Nevertheless, this paper aims to show that mutual interests and social interaction open a window to warmer peace and ensure the initiative's advancement.

\section{Methodology}

The study focuses on understanding a phenomenon, integrating Jordanian workers in the hospitality industry, as a humanistic approach. The objective is to capture the delicate social reality of Israelis and Jordanians and understand their standpoints, notions, beliefs, thoughts, experiences, behavior, and interactions. Hence, the qualitative research paradigm was chosen to study the phenomena in its natural settings to comprehend the meanings people attach to it. A single case study is examined and explored. It is a descriptive and instrumental case study that centers on a unique phenomenon. The studied phenomenon inspects the case's depth and scope from diverse angles such as security, culture, politics, and national interests.

Interviews enable us to seize the standpoints, perceptions, and assessments of various stakeholders. Thus they were chosen as the research tool to grasp Israelis and Jordanians' perspectives about the 'Eilat project'. The research population in the study is homogenous yet diverse. All the participants have a direct or an indirect connection to the hotel industry or the decision to incorporate Jordanians in Eilat's hospitality industry. The research population concludes 12 participants from four fields and different professions: politics (e.g., mayors), legislation (e.g., member of the Knesset), business (e.g., CEOs, entrepreneurs, and business people), and administration (e.g., hotel managers, administrators, human resource managers, coordinators, and line employees). The participants also differ regarding age, gender, work experience, education, and place of residence (i.e., participants from both sides of the border). The participants' similarities and variances provided a comprehensive point of view, inclusive and broad insights, and varied perspectives.

Twelve face to face interviews were conducted with diversified people from different lines of work. Four interview guides were prepared to address the participants' occupation and their relevance to Jordanian workers' integration in Eilat's hotel industry. The four interview formats 
were assigned to human resource managers, hotel managers, housekeeping managers (i.e., administrators), business people, and decision-makers (i.e., politicians, legislators).

The interviews included an assortment of questions that aimed to uncover the respondents' stances and attitudes towards integrating the Jordanian workers and questions that tried to comprehend the effect of economic, cultural, political, and security factors on the success or failure of this endeavor. For instance, administrators were asked why they prefer hiring Jordanian employees or what challenges they have encountered since the program's initiation. They were questioned about cultural differences, security issues, political implications, and economic impact. Decision-makers, on the other hand, were interviewed about the feasibility of the project, the action taken to implement the initiative, the obstacles they have encountered, the resources invested, and the economic outcomes.

The study also researched and examined various documents such as press releases, program proposals, survey data, organizational and institutional reports, public records, immigration policies, government decisions, labor and employment laws, administrative guidelines, municipal plans, regional forum statements, and bilateral agreements. These documents provided the necessary information about the context and background that enabled the incorporation of Jordanian workers in the hotel industry and helped strengthen the research's scientific method, credibility, and reliability.

\section{Findings}

The results emphasize the complex ties that prevail between Israel and Jordan. On the one hand, they depict the implications of cold peace. On the other hand, they illuminate the merits of the project that constitute a beacon of hope. A review of the data disclosed three motifs; Security issues and fear of terror attacks, bureaucracy, nationality, and citizenship. Table 1 presents the theme, category, and evidence.

Table 1: Israel-Jordan relations’ themes, categories, and evidence. 
Theme

Security issues

\section{Category}

Security issues constitute a significant portion of the project

The project is continuously controlled and monitored

\section{Evidence}

- "In Jordan, there is a large community of hostile Palestinian citizens; hence, there is a constant fear that people will take advantage of the project to commit terror attacks."

- "Security incidents result in a stricter examination, monitoring, control, and screening. The Shabak is difficult and making things harder for the Jordanians; they can announce an immediate stop of work. It happened to ten of our workers. The Jordanian Mukhabarat is even stricter; in the past, we had ten women working with us; now, they do not approve them at all."

Continuation of the project despite political disagreements or security events

The project marks a new step in the relationship

- "Previously, Jordanians did not want to hear about Israel. Now, you can talk about Israel in the media, in the streets. You can say I work in Israel. It is ok to say it now."

- "The Jordanians are not allowed to leave the hotel grounds. They enter Eilat with nothing but their clothes and cigarettes. Any gifts received from the hotels are translated into cash as the Jordanian side does not allow them to bring things with them."

- "The Jordanian workers are ambassadors. The program generates trust, kinship, and closeness. Both sides understand that the enemy is not so bad." 


\subsection{Security issues and fear of terror attacks}

Interviewees stressed that security issues still constitute a significant portion of the installment of the project.

S. S. 1 argued, "in Jordan, there is a large community of hostile Palestinian citizens; hence, there is a constant fear that people will take advantage of the project to commit terror attacks." M. I. H. maintained, "the peace is gentle. The conduct in Jordan is influenced by the diverse pressures that are imposed on the king. Disturbance to the delicate balance or security problems can paralyze the hospitality industry in Eilat." He added, "we are afraid of damage to the demographic characteristics of the city. We fear of illegal residents; thus, the city needs monitoring and control systems."

A. A. stated, "Israel has put all its eggs in one basket, and a significant incident could lead to a total collapse."

Moreover, interviewees pointed out that the project is continuously controlled and monitored by security agencies from both sides of the border.

E. K. explained that the "security incidents result in a stricter examination, monitoring, control, and screening. The Shabak is difficult and making things harder for the Jordanians; they can announce an immediate stop of work. It happened to ten of our workers. The Jordanian Mukhabarat is even stricter; in the past, we had ten women working with us; now, they do not approve them at all." M. E. clarified, "the process is lengthy. The screening of the applicants' $C V$ takes about two and a half months. The Shabak decides who is appropriate and who is eliminated."

A Jordanian human resources company manager illuminated, "we have a problem with security. It takes a long time to check the applications on both sides of the border. They are afraid that something may happen, as the incident in the port."

With that being said, interviewees underlined that the project continues despite political disagreements or security events.

S. S. 2 elucidated, "there were attempts to impede the project. But the support of intelligence agencies, law enforcement organizations, and political entities enabled its implementation." 
A. Z. clarified the stances of both sides of the border, "let's say from the Israeli side it is our interest to maintain the peace agreements, but for the Jordanians, we have seen ups and downs with all the events happening in Jerusalem and the closing of the embassy. In the Eilat district, there was no effect on the Jordanian workers. This goes to show that livelihood influences more than political views." S. S. 1 emphasized that "throughout history, mainly owing to mutual interests, the border did not close due to terror attacks or political differences between the countries."

A Jordanian human resources company manager maintained, "our government, our majesty, approves this project and is pushing this project up."

Interviewees also agreed that the project marks a new step in the relationship; hence, a policy change is necessary.

D. B. 2 asserted, "we need to change our perception of Jordan. It is not a hostile country, yes it does have some hostile residents, but as a whole, it is not hostile towards us." A. Z. agreed, "the Eilat region is different from other areas in the country bordering with Jordan,and it is regarded differently since the Eilat region has a unique committee; even in the peace agreement, there is an Aqaba/Eilat committee."

A Jordanian human resources company manager revealed that "previously, Jordanians did not want to hear about Israel. Now, you can talk about Israel in the media, in the streets. You can say I work in Israel. It is ok to say it now."

The results point out that security and safety issues constitute a vital and essential part of the Eilat project. In the probable future, supervision, inspections, and checkups are critical and crucial. Nevertheless, mutual interests have enabled the continuation of the project despite political disagreements or security hazards.

\subsection{Bureaucracy}

Bureaucracy is an integral part of the project. Interviewees mentioned the strict protocols, the background checks, the rules and procedures, and the codes of conduct. 
D. B. 2 stated, "there is an option for night shifts, but that would mean an increase in costs. The Ministry of Industry and Trade has yet to find a solution for the transfer fee. The hotels' dream is to allow the Jordanians to be integrated into the night shifts, but this will cost an extra 120 shekels per person." He added, "the Jordanians are not allowed to leave the hotel grounds. They enter Eilat with nothing but their clothes and cigarettes. Any gifts received from the hotels are translated into cash as the Jordanian side does not allow them to bring things with them."

A. Z. explained, "a regular border check cannot be conducted. The crossing had to be biometric. This is a complex procedure. Eventually, arrangements were made. Everyone worked together, including the hotel representatives, to figure out how all workers would cross in an hour. It was decided that biometric stations would be built, and procedures would be revised together with the authority of population."

S. S. 1 focused on the age restrictions, "there is an age restriction. The workers need to be at least 24 and no older than 45." While S. S. 2 centered on the movement restrictions, "the Jordanian workers ought to stay on hotel grounds. They are not allowed to wander around the city. Furthermore, it is forbidden to transfer commodities across the border."

S. L. maintained that "the Jordanian side is the one not allowing them to enter Jordan with gifts or purchases. And here they are not allowed to wander about unaccompanied. Those are the terms, and actually, we are ok with them. We find it reasonable, and about gifts, we translate them into cash and deposit it to their credit card." He indicated that "the reasons for not materializing the full allocation in each hotel was because of the Jordanian bureaucracy. Each Jordanian would go through a very fine filter by the Mukhabarat and on our side too. Slowly, we received all the Jordanians who were approved."

D. N. upheld "the fact that the Jordanians only work in Eilat and are obligated to return home at the end of the day prevents frictions."

V. G. stated, "the Jordanians are arriving at the border check in groups of five. They are allowed to take their wallet, passport, an open pack of cigarettes, a mobile phone, and a coat. As collateral, they need to check their passport at the border". He added, "the restrictions expedite the process. The check-in procedure is efficient and quick."

Similar to security issues, bureaucracy is primary to ensure the safety of the project. Yet, the wheels of bureaucracy turn slowly, impeding the advancement and progress of the initiative. 


\subsection{Nationality and citizenship}

There is a consensus that the project improves the relations between Israel and Jordan.

A. Z. claimed, "peace is created by people." D. B. 2 proclaimed, "our teams have very close relations with the Jordanians up to interpersonal relations. This program definitely strengthens the peace bond. Many relationships have evolved."

E. K. agreed, "if there is something that promotes peace, it is this project. Everything we grew up believing, reading, and hearing have faded. They see us differently."

S. S. 1 maintained, "the Jordanian workers are ambassadors. The program generates trust, kinship, and closeness. Both sides understand that the enemy is not so bad."

M. I. H. added, "this program is the real immune system that fights fundamentalists who try to harm this region. Projects like this exhibit the strength of the countries and normalize the relations with Jordan."

A Jordanian human resources company manager asserted, "before this project, the peace was only on a governmental level. I think this is the first right step since the signing of the

peace agreement. Now we feel that we have a real peace agreement between our countries. We can feel it in the streets, in the market. Before this project, the agreement was only in the offices between the governments, but now the people feel it."

D. N. specified an interesting point "the Jordanian worker has to leave Eilat at the end of each day to maintain his pride and dignity. If he stays in Israel for an extended period, it will endanger the unity of his family."

The results indicate that true and warm peace is attained through human connections. Social encounters generate dependence, empathy, and friendships and remove boundaries and misunderstandings. In summary, security issues and bureaucracy are entangled and inseparable from the project. However, joint interests and social contact might secure a warmer peace and protect the progress of the Eilat project. 


\section{Discussion and Conclusions}

The findings illustrate that security and amity are safeguarded via physical and diplomatic provisions and through personal connection and interaction between people.

Due to the hostile history between Israel and Jordan and ongoing disputes, security issues still constitute a significant portion of the project's installment. Fears of terror attacks and security issues are intertwined and attached to the project.

Hataley and Leuprecht argued that modifications in border policy are the result of negotiation between stakeholders, who share mutual interests, viewpoints, and values. They echo the societies and cultures they encompass and reflect specific social relationships in space and time (Hataley and Leuprecht 2018). The paper findings illustrate that borders are dynamic; They mirror the historical, political, and cultural framework of a state and articulate material and social mechanisms. Newman (Newman 2003) and Popescu (Popescu 2012)claimed that borders are institutions with distinctive rules and behaviors that shape their functionality, preservation, and modification. The findings show that borders influence the way people think of frontiers and mirror states' values and interests. When the relations are amicable, boundaries are viewed as a source of cooperation instead of prevention and control. To sum up, monitoring, screening, and inspections are imperative. Yet, shared interests, collaborations, and social interaction are steps in the right direction to assure a warmer peace and uphold the Eilat project's progress. Mutual understanding of the contemporary global multicultural workforce and joint interests enable the continuation of the project and empower cooperation and collaboration.

Parallel to security issues, bureaucracy is crucial to warrant the safety of the project. Bureaucracy is an integral part of the initiative. Strict protocols, background checks, rules, procedures, and codes of conduct are essential to its' continuation. Like political and administrative programs, the project has to cope with costs, fees, instructions, restrictions, complex procedures, paperwork, and border checks. These rules and constraints complicate the implementation of the project and inhibit its’ progression and development.

Nevertheless, bureaucracy assures order, safety, stability, and uniformity. Strict management presents opportunities to enhance security while simultaneously increasing cooperation, collaboration, and interests. Rusdiyant stated that the complexity of border control ought to be handled from both sides of the border. It has to be collaborative management, which includes 
domestic and international dimensions. (Rusdiyant 2017) Gerstein et al. specified that border management forms an equilibrium between security and the legal flow of people and goods. The study findings stress that bureaucracy and strict management offer opportunities to enhance security while concurrently improving cooperation, collaboration, and mutual interests. The results also strengthen Gerstein et al.'s claim that command, control, and communication enhance synchronization among organizations and are vital to controlling programs (Gerstein et al 2008).

The findings indicate a consent among interviewees that the project improves the relations between Israel and Jordan. There is a widespread agreement that the project cultivates interpersonal relationships and personal bonds. It has generated trust, kinship, and closeness. The project managed to achieve what 26 years of peace have failed to accomplish. It promoted interpersonal peace, helped change biased perspectives, advanced normalization, and aided the fight against fundamentalism. Thus, peaceful and honest relations between culturally and nationally contradicting societies can be achieved through human connections. Social encounters produce hope, relatedness, and familiarity and eliminate prejudice and misconceptions. Douglas highlights how groups in society constitue risk and build trust or distrust in institutions molding and regulating danger. The method presents a technique of decoding how and why people form judgments about peril and threat and stresses that views are not formed separately of social context (Douglas 1978). The paper findings suggest that risk and uncertainty notions can be modified through social interaction and close encounters. Though Israelis and Jordanians hold different political principles and beliefs, they can collaborate and form close relations.

Various facets hamper the progression of the project. Attributes such as historical background, security issues, bureaucracy, and political affiliation put a spoke in the initiative wheel and complicate the process. Yet, the project manages to flourish despite the setbacks. Its merits exceed difficulties and obstacles. In a short time, the project succeeded where political peace has failed. It forged friendships and business plans. Hence, all in all, the project's virtues surpass its shortcomings.

In summary, the incorporation of Jordanian workers in the hotel industry in Eilat presents a window of opportunity to start a new chapter in Israel and Jordan's relations. It might even invigorate the institutionalization and development of cooperation between the civilians of both 
countries. The Eilat project brings prospects for warmer relations and adds a civilian dimension to the governmental coordination that prevails between the countries. Perhaps via direct and daily interactions, Jordan and Israel's ties will progressively improve and expand and lead to a new era in the red sea.

The paper has several limitations. The main limitation derives from the nature of the research paradigm and the decision to focus on a single case study. Semi-structured interviews might generate social desirability. Hence, to overcome this shortcoming, no judgments were formed during meetings to allow for candid and sincere outlooks to be collected. Furthermore, qualitative research holds high validity yet maintains a low-reliability level. Therefore, to enhance the confidence in the findings, several methods were utilized to validate the data and display a robust body of conclusions. Moreover, the author might be defined as an involved researcher due to his vast experience in the hospitality industry. Yet, the proficiency and knowledge enabled him to find compelling data sources, locate prominent interviewees, and highlight significant outcomes of the 'Eilat project.' Future research should expand the research population in two aspects: size and scope. Regarding size, more people could be interviewed to validate the results. The study encompasses 12 participants; enlargement of the population will enhance reliability and generalization of the findings. The scope can also be expanded by interviewing people who are influenced by the integration of Jordanian workersfor example, the residents of Eilat, tourists, security agents, the workers' families in Jordan. This research is qualitative; future studies can incorporate quantitative features to strengthen the study's findings and conclusions. 


\section{References}

1. Avineri, Shlomo. "Price of A Cold Peace." The Jerusalem Post, 2000, p. 535 available online at: https://carnegieendowment.org/2000/10/13/priceof-cold-peace-pub, accessed on 17.10.2019.

2. Douglas, Mary. “Cultural Bias,” Royal Anthropological Institute Occasional Paper, no. 35, London: Royal Anthropological Institute, 1978, pp. 1-60.

3. Gerstein, Daniel M., Atler, Anthony, Davenport, Aaron C., Grill, Beth, Kadlec, Amanda, and Young, William. Managing International Borders. RAND Corporation, 2018, pp. 1-31.

4. Hataley, Todd and Leuprecht, Christian. "Determinants of Cross-Border Cooperation.” Journal of Borderlands Studies 33, No. 3, 2018, pp. 317-328.

5. Newman, David. “On Borders and Power: A Theoretical Framework.” Journal of Borderlands Studies 18, no. 1, 2003, pp. 13-25.

6. Popescu, Gabriel. Bordering and Ordering in the Twenty-first Century: Understanding Borders. Lanham: Rowman and Littlefield Publishers, 2012, pp.1-181.

7. Rusdiyant Rusdiyant, "Collaborative Border Management as the Strategic Revitalization of State Border Management in Indonesia," International Journal of Pure and Applied Mathematics 116, No. 24 2017, pp. 415-426.

8. Sallam, Moomen and Winter, Ofir. "Egypt and Israel: Forty years in the desert of cold peace.” Strategic Assessment 20, no. 3, 2017, pp. 21-34.

9. Schmuck, Richard. Practical Action Research for Change. Arlington Heights: IRI/Skylight Training and Publishing, 1997, pp. 1-156.

10. Sütalan, Zeynap. Explaining Cold Peace in The Middle East: The Cases of Egyptian-Israeli and Jordanian-Israeli Peace Processes, Doctoral dissertation. Ankara: The graduate school of social sciences of Middle East technical university, 2015, pp.1-227. 